Arq. Bras. Med. Vet. Zootec., v.68, n.2, p.265-270, 2016

\title{
Adaptação metabólica de equinos suplementados com óleos vegetais em testes de longa duração
}

\author{
[Metabolic adaptation of horses supplemented with vegetable oils during \\ low intensity exercise] \\ T.M. Oliveira ${ }^{1}$, M.J. Watanabe $^{2}$, A.P.L.M. Oliveira ${ }^{1}$, W.R. Fernandes ${ }^{1}$ \\ ${ }^{1}$ Faculdade de Medicina Veterinária e Zootecnia - Universidade de São Paulo - São Paulo, SP \\ ${ }^{2}$ Faculdade de Medicina Veterinária e Zootecnia - Universidade Estadual Paulista - Botucatu, SP
}

\begin{abstract}
RESUMO
Suplementação com óleos vegetais tem sido usada frequentemente na dieta de equinos atletas. O objetivo deste trabalho foi avaliar o metabolismo lipídico em testes de longa duração em equinos suplementados com óleo de soja ou óleo de arroz. Doze equinos da raça Árabe, não treinados, foram distribuídos em dois grupos, e cada grupo foi suplementado com óleo de soja ou de arroz por um período de seis semanas. Antes e após esse período, esses animais foram submetidos a um teste de longa duração (TLD) em esteira, quando foram coletadas amostras de sangue antes, durante e após o exercício. No TLD houve aumento nos valores séricos de ácidos graxos livres (AGL) e redução nos valores de triglicérides nos animais após suplementação nos dois grupos $(\mathrm{P}<0,05)$. Em ambos os grupos não houve alterações significativas nos valores de HDL no TLD após a suplementação. Nos animais após suplementação com óleo houve aumento da disponibilidade de energia no exercício de longa duração por meio do aumento de AGL e da manutenção dos níveis de lactato. As alterações no metabolismo lipídico causadas pela suplementação com óleo vegetal podem favorecer o desempenho desses animais em testes de longa duração.
\end{abstract}

Palavras-chave: equino, óleos vegetais, teste em esteira, ácidos graxos livres

\begin{abstract}
Vegetable oil supplementation has often been used in high performance horse feeding. The aim of the current study is to evaluate lipidic metabolism during the low intensity tests in fat-supplemented horses. Twelve untrained Arabian horses were divided into two groups, in which each group was supplemented with soybean oil or rice bran oil for a period of six weeks. Before and after this period they were submitted to low intensity test (TLD) on a high-speed treadmill, and blood samples were taken before, during and after exercise. In TLD there was an increase in serum free fat acids (AGL) levels and decrease in serum triacylglycerol levels in fat-supplemented horses in both groups $(P<0,05)$. No significant difference was observed in HDL values in TLD after supplementation. There was an increase in energy availability during low intensity exercise by increasing AGL and the maintenance of the lactate levels in fat-supplemented horses. Changes in the lipidic metabolism provided by vegetable oil supplementation are favorable for performance during TLD.
\end{abstract}

Keywords: equine, vegetable oils, treadmill tests, free fat acids

\section{INTRODUÇÃO}

Os lipídeos, que são utilizados para produção de energia, podem ser sintetizados no organismo ou obtidos pela alimentação. Os principais benefícios da suplementação com gordura têm

Recebido em 22 de setembro de 2014

Aceito em 16 de setembro de 2015

E-mail: tiagooliveira@usp.br sido observados em animais que realizam exercícios de resistência, para os quais a utilização de ácidos graxos para obtenção de ATP é muito importante, pois promove economia de glicogênio e gera uma menor quantidade de calor, melhorando, assim, o rendimento (González, 2007). 
Suplementações com lipídeos são cada vez mais frequentes na alimentação de cavalos atletas e sua administração a campo muitas vezes é empírica e associada a outros suplementos, o que dificulta a avaliação de seus reais efeitos. As pesquisas permitem avaliar com maior precisão os benefícios trazidos por esse tipo de suplementação associada ou não ao treinamento. Os efeitos da suplementação de óleos na alimentação em equinos estão descritos, em sua maioria, na literatura, associados ao treinamento (Orme et al., 1997; Dunnet et al., 2002).

As maiores concentrações de AGL no sangue têm sido reportadas após provas de longa duração, como as provas de enduro (Rose e Hodgson, 1994). Entretanto, segundo esses mesmos autores, não se pode assumir que altas concentrações de AGL no sangue sempre refletem em um aumento na utilização de gordura como fonte de energia. Se houver uma mobilização das reservas de gordura seguida por uma inibição da utilização destas devido a altas concentrações de lactato, os valores séricos de AGL estarão aumentados sem sua utilização como fonte de energia.

A concentração de triglicérides no sangue é claramente influenciada pela ingestão de gorduras. Fornecimentos maiores de gorduras pela alimentação diminuem os níveis séricos destes (Meyer, 1995). Essa diminuição pode ser secundária ao aumento da atividade da lipoproteína lipase (LPL), estimulada pela suplementação rica em gordura (Geelen et al., 1999). Entretanto, Moreira (2003), Freitas (2007) e Gonzaga (2008) não observaram alterações significativas nos valores séricos de triglicérides após período de suplementação com óleos vegetais.

Quando os triglicérides do VLDL são hidrolisados pela LPL, as partículas de apoproteínas, colesterol e fosfolipídeos são transferidas para o HDL. Esse processo explica a correlação direta entre a atividade da LPL e as concentrações de HDL, sugerindo que dietas ricas em gorduras aumentam a concentração de HDL (Geelen et al., 1999).

Equinos e humanos treinados são mais aptos a utilizar lipídeos para produzir energia do que carboidratos. Indivíduos treinados conseguem atrasar o início da fadiga por depleção de glicogênio (Marlin e Nankervins, 2002) e aumentam a capacidade de utilização dos triglicérides pelo músculo, devido à maior quantidade de enzimas envolvidas na $\beta$-oxidação, no metabolismo do ciclo de Krebs e na cadeia de transporte de elétrons (Lawrence, 1994; Mcardle et al., 1998).

Cavalos da raça Árabe geralmente são utilizados para provas de resistência, portanto necessitam de energia disponível por um longo período, obtida em sua maior quantidade pela metabolização dos lipídeos. Considerando que a suplementação com óleo possa contribuir para melhorias no desempenho desses animais, por um aumento de substrato para obtenção de energia e mudanças no metabolismo lipídico, o objetivo deste trabalho foi avaliar os efeitos da suplementação com óleo de arroz ou óleo de soja no metabolismo energético desses animais durante o exercício.

\section{MATERIAL E MÉTODOS}

Foram utilizados 12 equinos da raça Árabe, seis machos e seis fêmeas, com idade entre três e 13 anos, alojados durante o período experimental em seis piquetes de aproximadamente $25 \times 15 \mathrm{~m}$, com um cocho coberto para dois animais e bebedouro, com água ad libitum. Esses animais foram divididos em dois grupos: suplementados com óleo de arroz (GA) e suplementados com óleo de soja (GS). A divisão dos grupos foi baseada na idade, no sexo e no peso dos animais, de modo que houvesse dois grupos homogêneos em relação a esses três fatores. Esses foram alojados nos piquetes, sendo dois animais por piquete, onde foram adaptados ao feno e à ração que seriam utilizados durante o experimento.

O período de suplementação foi de seis semanas. $\mathrm{Na}$ primeira semana, para melhor adaptação à dieta, foram administrados junto à ração $100 \mathrm{~mL}$ de óleo por dia, e nas cinco semanas seguintes, $200 \mathrm{~mL}$ de óleo por dia. O óleo era misturado à ração no momento em que esta era oferecida ao animal no cocho. A ingestão completa da ração com o óleo era acompanhada para garantir que a quantidade de óleo oferecida fosse ingerida.

Testes de esforço progressivo foram realizados em todos os animais. Após a realização desses testes, os dados da frequência cardíaca foram utilizados para o cálculo do V150, índice que 
determinou a velocidade dos testes de longa duração. Os TLD foram aplicados em todos os animais um dia antes do início da suplementação e um dia após o término das seis semanas de suplementação, com o objetivo de se verificar a participação do metabolismo lipídico na geração de energia durante o exercício nos testes pré e pós-suplementação. Esses testes de longa duração consistiram em exercitar o animal por 60 minutos em esteira inclinada a $6 \%$, em uma velocidade correspondente ao V150 de cada animal. Foram coletadas amostras de sangue antes, durante (a cada 15min) e após o exercício para mensuração de ácidos graxos livres, triglicérides, HDL e lactato.

As amostras de soro para mensuração de ácidos graxos livres foram processadas pelo método enzimático colorimétrico, mediante a utilização de kit comercial (marca RANDOX ${ }^{\circledR}$ FA-115); para a mensuração de triglicérides, foi usada técnica descrita por Fossati e Prencipe (1982), por meio de reagente (Bio Systems M 11505c0013) e quantificado por espectrofotometria; para mensurar o HDL, foi utilizado kit comercial (BioSys Cholesterol HDL Direct) e quantificado por espectrofotometria; e o lactato no plasma foi obtido por meio do método de UV enzimático proposto por Westgard et al. (1972), com a utilização de kit comercial (Lactato Kovalent ART 1100075K, Kovalent do Brasil Ltda.).

A análise estatística foi realizada por ANOVA para medidas repetidas, que permitiu analisar conjuntamente os efeitos de tempo (durante o exercício), grupo (soja e arroz) e momento (pré e pós-suplementação). Para a análise inferencial, foi considerado um nível de significância de 5\% $(\alpha=0,05)$, e todos os testes tiveram conclusão sob hipótese bicaudal. O presente trabalho está de acordo com os princípios éticos de experimentação animal da Comissão de Ética no Uso de Animais da Faculdade de Medicina Veterinária e Zootecnia da Universidade de São Paulo, protocolado sob o número 1980/2010.

\section{RESULTADOS}

Com exceção de dois animais que não aceitaram a ração com óleo de arroz na manhã do primeiro dia de suplementação, houve uma boa aceitação dos óleos por parte dos animais suplementados, que ingeriam completamente a ração e o óleo oferecido. Não foram observadas alterações nas fezes, e nenhum animal apresentou sinais de doenças gastrointestinais durante o experimento.

Os valores séricos de AGL apresentaram-se crescentes ao longo do exercício e após 10 minutos do término da atividade, tanto nos testes pré como nos pós-suplementação $(\mathrm{P}<0,01)$. Houve um aumento significativo nos níveis séricos de AGL nos animais suplementados, sendo esse aumento maior no GS no repouso em comparação ao GA $(\mathrm{P}<0,05)$ (Fig.1).

Os níveis séricos de triglicérides apresentaram concentrações crescentes durante os TLD realizados pré-suplementação e nos dois grupos pós-suplementação $(\mathrm{P}<0,01)$. Dez minutos após o exercício, houve uma queda acentuada nesses valores em relação ao fim do exercício. Nos testes após a suplementação, os níveis séricos de triglicérides foram menores em todos os momentos em relação aos testes présuplementação $(\mathrm{P}<0,01)$ (Fig. 2).

A concentração de HDL apresentou variação em relação ao repouso apenas nos momentos 15 e 30 minutos. Entretanto, não houve efeito da suplementação nos dois grupos.

Os níveis plasmáticos de lactato aumentaram apenas nos momentos $60 \mathrm{~min}$ e $10 \mathrm{~min}$ após o exercício nos dois grupos $(\mathrm{P}<0,01)$, porém de maneira semelhante para ambos os grupos nas duas situações analisadas. Não houve aumento exponencial nos valores plasmáticos de lactato durante e após o exercício.

A velocidade em que os animais realizaram o teste de longa duração (V150) variou de $2,7 \mathrm{~m} / \mathrm{s}$ a $3,7 \mathrm{~m} / \mathrm{s}$, de acordo com a curva da frequência cardíaca de cada animal nos testes de esforço progressivo. Todos os equinos realizaram os testes de longa duração ao trote. 


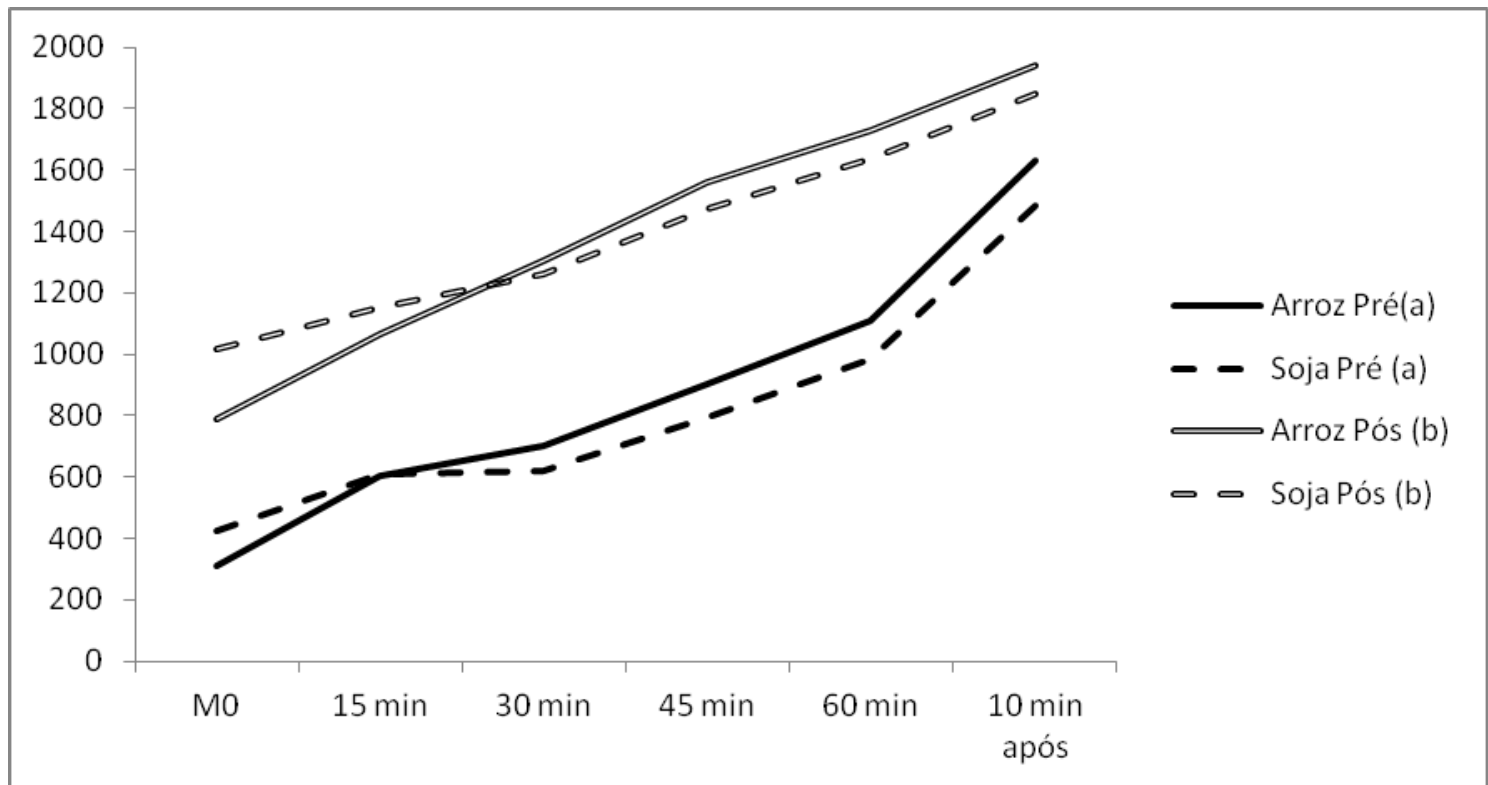

Figura 1. Concentração sérica de AGL ( $\mu \mathrm{mol} / \mathrm{L})$ antes (M0), durante (15 min, $30 \mathrm{~min}, 45 \mathrm{~min}$ e $60 \mathrm{~min})$ e após (10 min após) o TLD em equinos pré e pós-suplementação com óleo de soja ou óleo de arroz. Letras minúsculas diferentes diferem estatisticamente entre si.

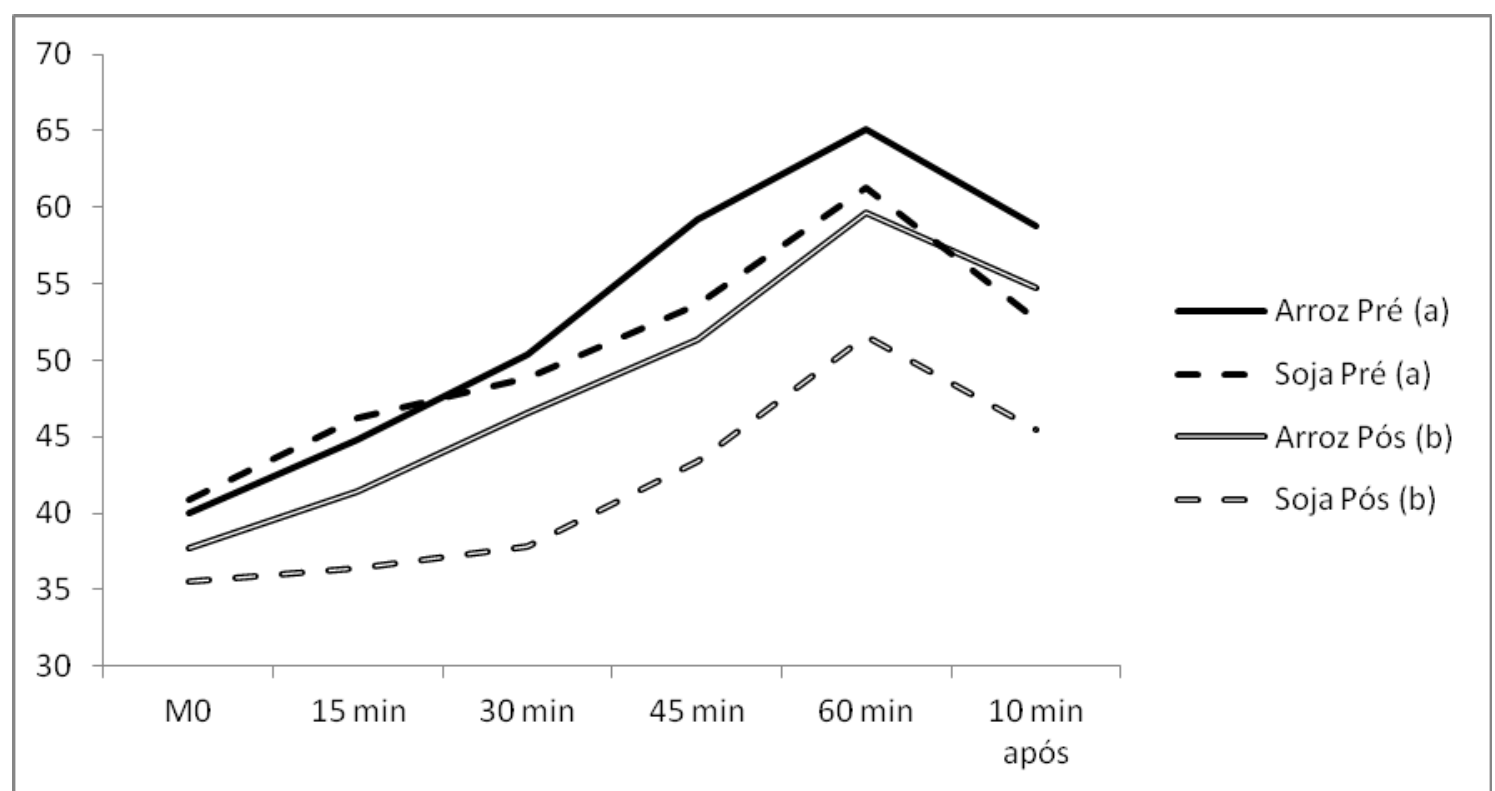

Figura 2. Concentração sérica de triglicérides (mg/dL) antes (M0), durante (15 min, 30 min, 45 min e 60 min) e após (10 min após) o TLD em equinos pré e pós-suplementação com óleo de soja ou óleo de arroz. Letras minúsculas diferentes diferem estatisticamente entre si.

\section{DISCUSSÃO}

Segundo Frape (2008), a inclusão de gorduras na dieta proporciona alterações no metabolismo lipídico após seis a 11 semanas de suplementação. No presente trabalho, observaram-se alterações significativas nas concentrações de AGL e triglicérides após seis semanas de suplementação em ambos os grupos, GA e GS. Dunnett et al. (2002) encontraram resposta metabólica após três semanas de suplementação com óleo vegetal, porém, dentro 
de cinco semanas após o término da suplementação, as concentrações séricas dos componentes lipídicos voltaram ao valor basal. Portanto, a suplementação com óleo tem efeitos transitórios e depende do seu uso contínuo.

O aumento dos níveis séricos de AGL observado após a suplementação foi significativo para os dois grupos, no entanto, no GS, houve um aumento mais acentuado nesses níveis em relação ao GA quando foram considerados os animais em repouso. Entretanto, durante o exercício, esse aumento nos valores séricos de AGL foi semelhante entre os dois grupos após a suplementação. Essas altas concentrações de AGL seguidas da manutenção dos níveis plasmáticos de lactato sugerem um aumento na utilização de gordura como fonte de energia (Rose e Hodgson, 1994; Duren et al., 1999), indicando, assim, uma adaptação dos equinos à nova disponibilidade energética.

Orme et al. (1997) e Freitas (2007) não encontraram valores séricos de AGL elevados em animais suplementados com óleos vegetais. Entretanto, esses autores realizaram a suplementação em animais treinados, os quais apresentam maior capacidade de utilização dos AGL e dos triglicérides pelo músculo, devido à maior quantidade de enzimas envolvidas na $\beta$-oxidação, no metabolismo do ciclo de Krebs e na cadeia de transporte de elétrons (Lawrence, 1994; Mcardle et al., 1998). No presente estudo, os animais permaneceram sem treinamento durante a suplementação, o que possibilitou aumento na disponibilização dos AGL no sangue e utilização destes, corroborando os resultados obtidos por Goodman (1973), que também realizou seu experimento com animais não treinados, justificando esse resultado aparentemente conflitante.

No momento pós-exercício, a concentração de AGL persiste elevada mesmo após o fim da atividade física. Esse fato ocorre devido à necessidade de obtenção de energia pelas células musculares que ainda mantêm relativa atividade. Porém, devido ao fim do exercício, há uma diminuição na mobilização da gordura do tecido adiposo, que pode ser confirmada pela queda nos valores séricos de triglicérides no pós-exercício.

A concentração de triglicérides no sangue apresentou valores menores nos animais após o período de suplementação nos dois grupos, sendo influenciada pela ingestão de gorduras, como relatado por Meyer (1995). Segundo Geelen et al. (1999), essa diminuição pode ser secundária a um provável aumento da atividade da LPL, estimulada pela suplementação rica em gordura. Geelen et al. (2001) afirmam que há uma relação direta entre o maior consumo de dietas ricas em gorduras e uma atividade elevada da LPL. Durante o exercício, os valores de triglicérides aumentaram gradativamente tanto nos grupos pré como nos pós-suplementação, devido à maior mobilização destes do tecido adiposo para a corrente sanguínea, onde são hidrolisados pela LPL para servir de substrato energético durante o exercício.

Os valores de HDL no soro aumentaram no momento 15 min e diminuíram no momento 30 min. Com exceção desses dois momentos, durante o restante do exercício os valores permaneceram sem variações. O HDL foi uma variável influenciada por alguns valores diferentes entre os cavalos durante o exercício, pois os grupos não apresentaram valores homogêneos. Provavelmente a ocorrência de um pico de diminuição foi influente no resultado da análise, como visto no momento $15 \mathrm{~min}$.

Ao contrário dos resultados obtidos no presente estudo, Geelen et al. (2001) demonstraram um aumento nos níveis séricos de HDL devido à suplementação com óleo vegetal. Segundo Geelen et al. (1999), os triglicérides do VLDL são hidrolisados pela LPL e liberam partículas de apoproteínas, colesterol e fosfolipídeos, que, por sua vez, são transferidas para o HDL, promovendo um aumento na concentração sérica dessa lipoproteína. Esse processo explica a correlação direta entre o aumento da atividade da LPL e as altas concentrações de HDL. No presente trabalho, esses processos não foram observados estatisticamente, provavelmente em razão de os animais não apresentarem valores homogêneos para essa variável.

Durante o exercício, não foi observada influência da suplementação com óleo vegetal nos valores plasmáticos de lactato. Entretanto, não houve, durante o exercício, aumento exponencial dos valores plasmáticos de lactato, pois os valores sofreram pouca variação. Esse resultado pode ser explicado pelo fato de que se trabalhou com o V150 para determinar a velocidade em que seria 
realizado esse teste. Segundo Juzado et al. (2005), o V150 é um índice que permite trabalhar com o animal em metabolismo predominantemente aeróbico, portanto compatível com os valores de lactato encontrados no presente estudo.

\section{CONCLUSÕES}

A inclusão de óleo de arroz ou óleo de soja na alimentação de equinos promoveu uma maior quantidade de substrato energético, disponibilizando energia que pode ser utilizada conforme a necessidade. O metabolismo lipídico dos animais foi influenciado de maneira semelhante pelos dois tipos de óleo, com aumento nas concentrações séricas de AGL e redução nos valores de triglicérides.

\section{REFERÊNCIAS}

DUNNETT, C.E., MARLIN, D.J.; HARRIS, R.C. Effect of dietary lipid on response to exercise: relationship to metabolic adaptation. Equine Vet. J.Suppl., v.34, p.75-80, 2002.

DUREN, S.; PAGAN, J.; HARRIS, P.; CRANDELL, $\mathrm{K}$. Time of feeding and fat supplementation affect plasma concentrations of insulin and metabolites during exercise. Equine Vet. J.Suppl., v.30, p.479-484, 1999.

FRAPE D. Nutrição e alimentação de equinos. 3.ed. São Paulo: ROCA, 2008. 616p.

FREITAS E. V.V. Variáveis fisiológicas em equinos submetidos a dietas com adição de óleo vegetal e a exercício físico de longa duração. 2007. 54f. Tese (Doutorado em Zootecnia) - Faculdade de Ciências Agrárias e Veterinárias, Universidade Estadual Paulista, Jaboticabal, SP.

FOSSATI, P.; PRENCIPE, L. Serum triglycerides determined colorimetrically with an enzyme that produces hydrogen peroxide. Clin. Chem., v.28, p.2077-2080, 1982.

GEELEN, S.N.J., JANSEN, W.L., VAN OLDRUITENBORGH-OOSTERBAAN, M.M. et al. Fat feeding increases equine heparin-released lipoprotein lipase activity. J. Vet. Int. Med., v.15, p. $478-481.2001$
GEELEN, S.N.J., VAN OLDRUITENBORGHOOSTERBAAN, M.M.; BEYNEN, A. Dietary fat supplementation and equine plasma lipid metabolism. Equine Vet. J.Suppl., v.30, p.475-478, 1999.

GOODMAN, H.M.; VANDER NOOT, G.W.; TROUT, J.R.; SQUIBB, R.L. Determination of energy source utilized by the light horse. J. Anim. Sci., v.37, p.56-62, 1973 .

GONZAGA I. V.F. Suplementação com óleo de arroz semi-refinado com alto teor de gama-orizanol na dieta de garanhões. 2008. 87f. Dissertação (Mestrado em Medicina Veterinária) - Faculdade de Medicina Veterinária e Zootecnia, Universidade de São Paulo, Pirassununga, SP.

GONZALEZ G.O. Nutrición y alimentación del caballo atleta. In: BOFFI, F.M. Fisiologia del ejercicio em equinos. Buenos Aires: Intermédica, 2007. p.205222.

JUZADO, A.M.; HERNÁNDEZ, M.B.; LUCAS, G.R. et al. Estimación del estado de forma física en caballos de deporte mediante índices de funcionalidad. Rev. Cient., v.15, p.217-226, 2005.

LAWRENCE L. Nutrition and the athletic horse. In: ROSE, D.R.; HODGSON, R.J. The athletic horse. Philadelphia: Saunders, 1994. p.205-230.

MARLIN, D.; NANKERVIS, K. Equine exercise physiology. Oxford: Blackwell Science, 2002. 296p.

MCARDLE, W.D.; KATCH, F.I.; KATCH, V.L. Carboidratos, gorduras e proteínas. In:

Fisiologia do exercício: energia, nutrição e desempenho humano. 4.ed. Rio de Janeiro: Guanabara Koogan, 1998. p.12-22.

MEYER H. Alimentação de cavalos. São Paulo: Varela, 1995. 303p.

MOREIRA A. M. F. O. Avaliação da aceitabilidade e digestibilidade de dietas para equinos com diferentes fontes de óleo vegetal. 2008. 70f. Dissertação (Mestrado em Medicina Veterinária) - Faculdade de Medicina Veterinária e Zootecnia, Universidade de São Paulo, Pirassununga, SP.

ORME, C.E.; HARRIS, R.C.; MARLIN, D.J.; HURLEY, J. Metabolic adaptation to fat supplemented diet by the thoroughbred horse. Br. J. Nutr., v.78, p.443-458, 1997.

ROSE, R.J.; HODGSON, D.R. The athletic horse. Philadelphia: Saunders, 1994. 497p.

WESTGARD, J.O.; LAHMEYER, B.L.; BIRNBAUM, M.L. Use of the Du Pont "automatic clinical analyzer" in direct determination of lactic acid in plasma stabilized with sodium fluoride. Clin. Chem., v.18, p.1334-1338, 1972. 